\title{
Evaluation of medical faculty students' knowledge and attitudes about HPV infection and HPV vaccine
}

\author{
Yeşim Ayazöz $^{1}$ and Dursun Cadirci ${ }^{2}$ \\ ${ }^{1}$ Oğuzeli Contry State Hospital \\ ${ }^{2}$ Harran Universitesi
}

February 28, 2021

\begin{abstract}
Background: Human papilloma virus (HPV) infection is the most common sexually transmitted viral disease. It was aimed to evaluate the knowledge levels and attitudes of medical faculty students about HPV infection and vaccine. Methods: Our descriptive cross-sectional study; was made with the medical faculty students studying at the Harran University Faculty of Medicine in the 2019-2020 academic year. A total of 645 students were reached, excluding those who refused to participate in the study and those who were not at the faculty or hospital for any reason. Data were collected using a questionnaire method. NCSS 2007 program was used for statistical analysis. Results: 645 students were included in this study ( $52.9 \%(\mathrm{n}=341)$ is male, $47.1 \%(\mathrm{n}=304)$ is female, and average age of them is $21.46 \pm 2.39$ years $) .75 .3 \%$ of the students stated that they have information about HPV infection. The HPV infection knowledge level scores of the married were higher than the singles $(\mathrm{p}=0.005 ; \mathrm{p}<0.01) .51 .2 \%$ of the students stated that they had knowledge about the HPV vaccine. HPV vaccine knowledge level scores of women were compared to men $(\mathrm{p}=0.019 ; \mathrm{p}<0.05)$; and the scores of married people were also higher than singles $(\mathrm{p}=0.016 ; \mathrm{p}<0.05)$. Only $1.9 \%$ of the students had the HPV vaccine. Conclusion: In our study, it was seen that the medical faculty students' knowledge about HPV infection and vaccine was not sufficient, and the methods that should be used to provide more effective education should be determined. We believe that it will be beneficial to add the HPV vaccine to the national vaccine program in our country.
\end{abstract}

\section{Evaluation of medical faculty students' knowledge and attitudes about HPV infection and} HPV vaccine

\section{Abstract}

Background: Human papilloma virus (HPV) infection is the most common sexually transmitted viral disease. It was aimed to evaluate the knowledge levels and attitudes of medical faculty students about HPV infection and vaccine.

Methods: Our descriptive cross-sectional study; was made with the medical faculty students studying at the Harran University Faculty of Medicine in the 2019-2020 academic year. A total of 645 students were reached, excluding those who refused to participate in the study and those who were not at the faculty or hospital for any reason. Data were collected using a questionnaire method. NCSS 2007 program was used for statistical analysis.

Results: 645 students were included in this study ( $52.9 \%(\mathrm{n}=341)$ is male, $47.1 \%(\mathrm{n}=304)$ is female, and average age of them is $21.46 \pm 2.39$ years). $75.3 \%$ of the students stated that they have information about HPV infection. The HPV infection knowledge level scores of the married were higher than the singles $(\mathrm{p}=$ $0.005 ; \mathrm{p}<0.01) .51 .2 \%$ of the students stated that they had knowledge about the HPV vaccine. HPV vaccine knowledge level scores of women were compared to men $(\mathrm{p}=0.019 ; \mathrm{p}<0.05)$; and the scores of married people were also higher than singles $(\mathrm{p}=0.016 ; \mathrm{p}<0.05)$. Only $1.9 \%$ of the students had the HPV vaccine. 
Conclusion: In our study, it was seen that the medical faculty students' knowledge about HPV infection and vaccine was not sufficient, and the methods that should be used to provide more effective education should be determined. We believe that it will be beneficial to add the HPV vaccine to the national vaccine program in our country.

Keywords: HPV, HPV Vaccines, Medical Students, Knowledge, Attitude

İNFORMATION: Hpv infection and vaccine is an important issue for public health. HPV vaccine is effective in preventing infection but are not yet in the national immunization program in Turkey. Our study is the most comprehensive study conducted in our country in terms of both the sample size and the inclusion of students in every period of medical education. In our study, it was seen that the knowledge level of medical faculty students about HPV infection and vaccine was not sufficient, and the methods that should be used to provide more effective education should be determined. In addition, we believe that if the HPV vaccine is added to the national vaccine program in our country, as in many countries, the incidence of HPV infection and related diseases will decrease.

\section{Evaluation of medical faculty students' knowledge and attitudes about HPV infection and HPV vaccine}

\section{INTRODUCTION}

Human papilloma virus (HPV) infection is the most common sexually transmitted viral disease. Most HPV infections are asymptomatic and are transmitted by sexual contact. ${ }^{1} \mathrm{HPV}$ is an icosahedral capsid, circular double-stranded, non-enveloped DNA virus from the Papillomaviridae family, which has been established to be associated with cervical cancer. This virus, which causes dysplasia in the transformation zone of the cervix, causes precancerous changes. ${ }^{2}$

More than 200 types of HPV have been identified. ${ }^{2}$ HPV types 6 and 11 are found in $90 \%$ of cases of condylomata acuminata (genital warts). HPV types $16,18,31$ and 35 are associated with squamous cell cancers of the vulva, vagina, cervix, penis and anus. ${ }^{1}$ HPV types 16 and 18 increase the risk of cervical cancer approximately 200 times. Epidermodysplasia verruciformis, head and neck cancers, and recurrent respiratory papillomatosis are other HPV-related diseases. ${ }^{3}$

In the research conducted in Turkey, the prevalence of HPV infection in women who were between $2-20 \%{ }^{4}$ In the United States of America (USA), the incidence of HPV is particularly high among college students $(35-43 \%)$, minorities and people with more than one sexual partner. ${ }^{1}$ The most important risk factors for transmission; the onset of sexual intercourse at an early age, the presence of many sexual partners and the presence of many sexual partners of the male partner. ${ }^{5}$ Genital HPV infection is most commonly detected in sexually active women between the ages of $15-24 .^{6}$

There are three different HPV vaccines approved by the US Food and Drug Administration (FDA). The first of these vaccines is the quadrivalent vaccine. Quadrivalent vaccine is developed against types 6 and 11 that cause genital warts, 16 and 18 that cause cervical cancers and is recommended to be administered in three doses at 0,2 and 6 months. The target population of the vaccine is young men and women between the ages of 9-26. Bivalent vaccine was developed against types 16 and 18 and it is recommended to be administered in three doses at 0,1 and 6 months. The 9-valent vaccine targets HPV types $6,11,16,18,31,33,45,52$ and 58 and was approved by the FDA in 2014 for women aged 9-26 and men aged 9-15 years. ${ }^{7}$

ACOG (The American Congress of Obstetricians and Gynecologists) recommends that the vaccine be administered between the ages of 9-26. Recommended for the first dose in girls and boys ages 11-12. HPV-DNA tests and serological tests are not required before vaccination. Routine cervical cancer screening should continue after vaccination. $^{8}$

In this study, it was aimed to evaluate the knowledge levels and attitudes of medical faculty students about HPV infection and vaccine. Our study is the most comprehensive study conducted in our country in terms of both the sample size and the inclusion of students in every period of medical education. We think that our 
study will increase awareness about HPV infection and vaccine and contribute to an increase in vaccination rates.

\section{METHODS}

This study is a descriptive cross-sectional study. The universe of the research; medical faculty students studying at Sanliurfa Harran University (HRU) Faculty of Medicine during the 2019-2020 academic year were formed. There are 182 in the 1 st grade, 150 in the 2 nd grade, 154 in the 3rd grade, 136 in the 4 th grade, 114 in the 5 th grade and 114 in the 6 th grade, and the total number of students is 850 . In this non-sampling study, it was aimed to reach the entire population. A total of 645 students were reached, excluding those who refused to participate in the study and those who were not at the faculty or hospital for any reason.

A sociodemographic data form consisting of 14 questions and a questionnaire form consisting of 25 questions prepared by examining previous studies on the subject were created. In the questionnaire form, there were a total of 16 information questions, 7 of which were basically measuring knowledge levels about HPV infection, 9 measuring knowledge levels about HPV vaccine, and 6 questions that evaluated attitudes about vaccination. Appropriate filling of the questionnaires was carried out by the research assistant who conducted the research by visiting the relevant departments.

NCSS (NumberCruncher Statistical System) 2007 (Kaysville, Utah, USA) program was used for statistical analysis. Descriptive statistical methods (mean, standard deviation, median, frequency, percentage, minimum, maximum) were used while evaluating the study data. The compatibility of the quantitative data to normal distribution was tested by Shapiro-Wilk test and graphical analysis. Mann-Whitney U test was used for comparing quantitative variables that did not show normal distribution between two groups. The Kruskal Wallis test and the Bonferroni-Dunn test for paired comparisons were used for comparisons of three and more groups that did not show normal distribution. In comparison of qualitative data, Pearson Chi-Square test, Fisher'sExact test and Fisher-Freeman-Halton test were used. Statistical significance was accepted as $p$ $<0.05$.

This study was initiated with the approval of the Dean of the HRU Faculty of Medicine, dated 24.05.2019 and numbered 22621, and the approval of the HRU Faculty of Medicine Non-Invasive Clinical Research Ethics Committee with the 13.06.2019 dated, 06 numbered and 22 numbered approval.

\section{RESULTS}

Of the 645 students included in the study, $52.9 \%(\mathrm{n}=341)$ were male, $47.1 \%(\mathrm{n}=304)$ were female, with an average age of $21.46 \pm 2.39$ years. $97.5 \%(\mathrm{n}=629)$ of the students were single, $2.3 \%(\mathrm{n}=15)$ were married and $0.2 \%(\mathrm{n}=1)$ were widowed. $29.9 \%(\mathrm{n}=193)$ of the students live with their families, and $16.3 \%$ $(\mathrm{n}=105)$ smoke and $12.5 \%(\mathrm{n}=81)$ use alcohol. The distributions of sociodemographic characteristics are presented in Table 1.

Table 1. Distribution of Sociodemographic Characteristics

\begin{tabular}{llll}
\hline & & Min-Max (Median) & Mean \pm Sd \\
\hline Age (years) & & $17-33(21)$ & $21,46 \pm 2,39$ \\
\multirow{3}{*}{ Gender } & Male & $\mathbf{n}$ & $\mathbf{\%}$ \\
& Farital status & 341 & 52,9 \\
& Single & 304 & 47,1 \\
& Married & 629 & 97,5 \\
Grade & Widow & 15 & 2,3 \\
& 1.grade & 142 & 0,2 \\
& 2. grade & 94 & 22,0 \\
& 3. grade & 104 & 14,6 \\
& & & 16,1
\end{tabular}




\begin{tabular}{llll}
\hline & & Min-Max (Median) & Mean \pm Sd \\
\hline \multirow{5}{*}{ Living place } & 4. grade & 116 & 18,0 \\
& 5. grade & 91 & 14,1 \\
& 6. grade & 98 & 15,2 \\
& Government dorm & 191 & 29,6 \\
& Private dormitory & 72 & 11,2 \\
& Student house & 189 & 29,3 \\
Smoking & With the family & 193 & 29,9 \\
& No & 511 & 79,2 \\
& Yes & 105 & 16,3 \\
& Ex smoker & 29 & 4,5 \\
& No & 554 & 85,9 \\
& Yes & 81 & 12,5 \\
& Ex drinker & 10 & 1,6 \\
\hline
\end{tabular}

$75.3 \%(\mathrm{n}=486)$ of the students stated that they had knowledge about HPV infection. When the sources of information are examined; $85.8 \%(\mathrm{n}=417)$ were from school, $33.5 \%(\mathrm{n}=163)$ were from the internet, $14.2 \%$ $(\mathrm{n}=69)$ were from TV / newspapers / magazines, $21.6 \%(\mathrm{n}=105)$ were from healthcare professionals and $14.4 \%(\mathrm{n}=70)$ received information from their friends. The distribution of the answers given by the students to the questions measuring their knowledge level about HPV infection is presented in Table 2 .

Table 2. Distributions of Answers Given to Questions Measuring Knowledge Level About HPV Infection

-HPV infection causes cervical cancer and genital warts.

-HPV infection occurs only in women.

-HPV-related genital warts can be seen in both men and women.

-HPV infection ranks first among the causes of cervical cancer.

-HPV infection is transmitted from the mother to the baby through the infected birth canal sexually, body fluids or during -HPV infection is always symptomatic (showing signs).

-Monogamy, condom use and vaccination are effective in preventing HPV infection.

Correct answers are indicated in bold and italics in the table.

Based on the correct answers given by the students to the questions measuring their knowledge level about HPV infection, a knowledge level score was calculated. The minimum and maximum number of correct answers to 7 questions about HPV infection is 0 and 7 ; the correct answers given were collected by accepting 1 point. The scores obtained were converted to a scale of 100 in order to be standardized. The number of correct answers given by the students to the questions measuring their knowledge level about HPV infection varies between 0 and 7 , with an average of $4.17 \pm 2.56$. HPV infection knowledge level scores ranged from 0 to 100 , with an average of $59.56 \pm 36.60$.

No statistically significant difference was found between the HPV infection knowledge level scores according to gender $(\mathrm{p}>0.05)$. A statistically significant difference was found between the HPV infection knowledge level scores according to marital status $(\mathrm{p}=0.005 ; \mathrm{p}<0.01)$; scores of married students were higher than singles. A statistically significant difference was found between the HPV infection knowledge level scores by class $(\mathrm{p}=0.001 ; \mathrm{p}<0.01)$. The higher the class level, the higher the knowledge level score.

$51.2 \%$ ( $\mathrm{n}=486)$ of the students stated that they had knowledge about the HPV vaccine. The distribution of 
the answers they gave to the questions measuring the level of knowledge about the HPV vaccine is presented in Table 3.

Table 3. Distribution of Answers Given to Questions Measuring Knowledge Level About HPV Vaccine

\begin{tabular}{lcc}
\hline & True & T \\
\hline & n & T \\
-HPV vaccine has preventive properties of genital warts in both men and women and cervical cancer in women. & 312 & 4 \\
-HPV vaccine should only be given to girls. & 32 & 596 \\
-It is thought that administration of HPV vaccine to men may be beneficial. & 290 & 4 \\
- The ideal group for HPV vaccination is young men and women between the ages of 9-26. & 263 & 4 \\
-HPV vaccine should be done without being sexually active. & 74 & 1 \\
-HPV vaccine can be given to any age group. & 76 & 1 \\
-HPV vaccine is recommended as a single dose. & 275 & 4 \\
-After the HPV vaccine, side effects such as pain, redness and headache at the injection site may occur. & 206 & 3 \\
-HPV vaccine is not included in the national vaccination program and is available for a fee. & \\
\hline
\end{tabular}

Correct answers are indicated in bold and italics in the table.

Based on the correct answers given by the students to the questions measuring their knowledge level about HPV vaccine, a knowledge level score was calculated. The minimum and maximum number of correct answers to 9 questions about HPV vaccine is 0 and 9; the correct answers given were collected by accepting 1 point. The points obtained were converted to a scale of 100 in order to be standardized. The number of correct answers given by the students to the questions measuring their level of knowledge about HPV vaccine varies between 0 and 9 , and the average is $3.47 \pm 2.69$. HPV vaccine knowledge level scores ranged from 0 to 100 , with an average of $38.55 \pm 29.94$.

A statistically significant difference was found between the HPV vaccine knowledge level scores according to gender $(\mathrm{p}=0.019 ; \mathrm{p}<0.05)$; the scores of women were higher than men. A statistically significant difference was found between the HPV vaccine knowledge level scores according to marital status $(\mathrm{p}=0.016 ; \mathrm{p}<0.05)$; scores of married students were higher than singles. A statistically significant difference was found between the HPV vaccine knowledge level scores by class $(\mathrm{p}=0.001 ; \mathrm{p}<0.01)$. The higher the class level, the higher the knowledge level score. The distribution of attitudes towards HPV vaccine is presented in Table 4.

Table 4. Distribution of Attitudes About HPV Vaccine

Whether or not to have HPV vaccine

Status of wanting to get HPV vaccine $(\mathrm{n}=633)$

Reason for not wanting to get HPV vaccine $(\mathrm{n}=98)$

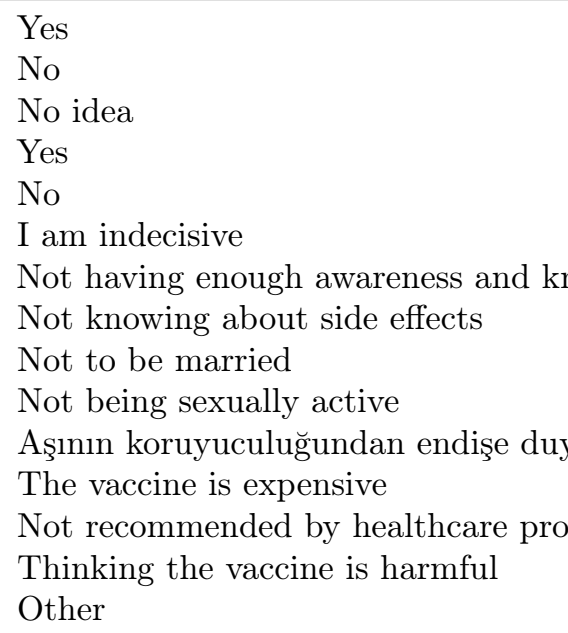


Whether to have HPV vaccine if it was free $(\mathrm{n}=633)$

Ideas on adding HPV vaccine to national vaccine program

The state of thinking that HPV infection and vaccine are important after the survey
Yes

No

I am indecisive

Yes

No

I am indecisive

Yes

No

\section{*Multiple selections have been made}

The status of wanting to have HPV vaccine according to gender does not show a statistically significant difference $(\mathrm{p}>0.05)$. The status of wanting to have HPV vaccine shows a statistically significant difference according to marital status $(\mathrm{p}=0.048 ; \mathrm{p}<0.05)$. The ratio of wanting to be vaccinated is higher among married people than singles.

\section{DISCUSSION}

Our study was conducted with a total of 645 medical faculty students studying at Şanllurfa HRU Faculty of Medicine. In order for the medical faculty students, who are the doctors of the future, to guide the society, first of all, they should have full awareness and knowledge on this subject. In the study conducted by Çetin et al. with adolescent girls between the ages of 13-18, $77.8 \%$ of the participants had no knowledge of HPV, only $22.2 \%$ stated that they had heard of HPV before. ${ }^{9}$ In our study, the rate of students expressing that they knew about HPV infection was higher. Students who participated in our study may have a higher rate of expressing their knowledge about HPV infection due to their high level of success and their older age.

The sources from which students who stated that they had knowledge about HPV infection received the most information were school (85.8\%), internet (33.5\%), healthcare professionals $(21.6 \%)$, friends $(14.4 \%)$ and TV / newspaper / journal (14.2\%). In a similar study conducted with 340 medical faculty students, the most informational source about HPV infection was found as the learning process in the faculty, as in our study. ${ }^{10}$ In the study conducted by Güdücü et al. with a total of 603 nursing and medical faculty students and nurses, $37.1 \%$ of them were school, $31.7 \%$ was internet, $35.8 \%$ was newspaper-television when the sources of information on HPV were investigated. ${ }^{11}$

In our study, knowledge level score about HPV infection was found higher in married students than singles. This may be due to the fact that married women who are sexually active are more sensitive to this issue, since HPV is a sexually transmitted infection.

In the study conducted by Unutkan et al. with 468 female students studying at a health college, the rate of knowing about HPV infection and vaccine increased as the grade level increased. ${ }^{7}$ In similar studies conducted on medical faculty students; it was found that the students studying in the clinic had more information about HPV infection and vaccines than pre-clinical students. ${ }^{10,12}$ In our study, a statistically significant difference was found between the rates of having knowledge about HPV infection by class, and the higher the grade, the higher the knowledge rate.

In a similar study conducted with 340 medical school students, the rate of knowing the transmission routes of HPV was found to be $35.8 \%$, which is lower than our study. ${ }^{10}$ In the study conducted by Güdücü et al., $76 \%$ of the participants stated that HPV is a sexually transmitted disease. ${ }^{11}$ In our study, the rate of knowing the transmission routes of HPV infection was found to be lower.

In the study conducted by Naki et al. with doctors and other healthcare professionals who are not physicians, $49.8 \%$ of the participants agreed with the statement "HPV is generally symptomatic", and it was found to be significant in favor of doctors when the doctor and other healthcare professionals were compared in this 
statement $(\mathrm{p}<0.001) .{ }^{13}$ In our study, the rate of students knowing the clinical course of HPV is similar to the study of Naki et al.

$25 \%$ of the participants answered "yes" to the proposition "The use of condoms is protective against HPV" in a study by Tolunay et al. on 228 physicians, 131 of which were pediatricians and 97 obstetricians. ${ }^{14}$ In the study conducted by Özsürekçi et al. with 226 pediatricians in $2011,49 \%$ of them answered the same statement as "I agree ". ${ }^{15}$ In our study, the rate of knowing the ways of protection from HPV was found higher than both studies.

The fact that the genital system is immature in adolescents increases the risk of genital infections. The age group most affected by HPV infection and related diseases is between the ages of 20-24. Therefore, it is important to inform adolescents in the early period and to complete the vaccine doses. From this point of view, it is a sad finding that nearly half of the students (48.8\%) who participated in our study had never heard of HPV vaccine before.

In a similar study Önsüz et al. conducted with 166 students who had an internship in gynecology and obstetrics in a medical school; they stated that only $55.4 \%$ of the medical faculty students studying in the clinic had information about the HPV vaccine. ${ }^{12}$ In our study, the rate of students stating that they knew about the vaccine was similar. The rate of having information about the vaccine $(51.2 \%)$ is lower than the rate of having information about the infection (75.3\%); it may be due to the HPV vaccine being a new vaccine and not being included in our national vaccine program.

In the study of Unutkan et al., $13.7 \%$ of the students knew that the vaccine should be administered without being sexually active. ${ }^{7}$ In our study, the rate of knowing the time of vaccine administration is higher in students. In a similar study conducted on medical faculty students, it was found that $12.3 \%$ of the students knew the target population of vaccines and $82.1 \%$ did not have information about the vaccine doses. ${ }^{10}$ In our study, the rate of knowing the target population of vaccines is higher and the rate of knowing the vaccine doses is lower.

Women's knowledge level scores (41.45) about HPV vaccine were higher than men (35.97) and married's scores (57.04) were higher than singles (38.11). The reason why the knowledge level score of men is lower than that of women; due to the fact that cervical cancer, which can be fatal, is not seen in the male gender, it may be that men see themselves less at risk for HPV-related diseases and do not show enough interest in vaccination.

It was found that the HPV vaccine status of the students participating in our study was quite low. In a similar study conducted on 340 medical faculty students, the rate of students getting HPV vaccine was $2.6 \%$ and the rate of students who wanted to have the vaccine was found to be $47.6 \% .{ }^{10}$ In the study conducted by Güdücü et al., the rate of getting the HPV vaccine was $4 \% .{ }^{11}$ In a study conducted on 174 medical residents, the rate of HPV vaccination was reported to be $1.7 \%$, similar to our study. ${ }^{16}$

In our study, the most important reason for not wanting to have HPV vaccine is the lack of sufficient knowledge and information about the vaccine, suggesting that the vaccination rates will increase if the necessary training about the vaccine is provided and supported. $38.1 \%$ of the students who did not have HPV vaccine and had no idea about it stated that they would like to have it if the vaccine is free. This situation shows us that the cost of the vaccine is one of the biggest obstacles to getting the vaccine. In the study conducted by Çeşmeci and his friends in 2015 with 208 intern doctors studying at Hacettepe University Faculty of Medicine; $41.8 \%$ of intern doctors stated that the vaccine cost was high, $28.4 \%$ were not covered by the health insurance, $27 \%$ thought that the vaccine was unnecessary, and $32.2 \%$ stated that they did not have the vaccine because they were male. ${ }^{17}$

In the study conducted by Rathfisch et al. with 605 university students studying at Istanbul University in 2014 , it was stated that $44.4 \%$ of women and $25.8 \%$ of men answered "yes" to the question "Would you like to have the HPV vaccine ". ${ }^{18}$ In our study, women and men answered "yes" at a similar rate to the question "Would you like to have the HPV vaccine". 
According to the study of Özsurekçi et al., $70 \%$ of the physicians want the HPV vaccine to be added to the national vaccination calendar. ${ }^{15}$ In the study conducted by Tolunay et al., $70 \%$ of the participants answered as "HPV vaccine should be added to the routine vaccination schedule ". ${ }^{14}$ In our study, the rate of students asking for the HPV vaccine to be added to the national vaccination program was lower.

\section{CONCLUSION}

As a result; in our study, it was seen that the medical faculty students' knowledge about HPV infection and vaccine was not sufficient, and the methods that should be used to provide more effective education should be determined. The education process on HPV infection and vaccine should not be limited to the medical school, but should be added to the primary and high school curricula, and the society should be informed at an earlier age. The knowledge and awareness level of healthcare professionals should be increased with in-service training programs and support projects in their later professional lives.

The fact that the majority of the medical faculty students who are in the risk group in terms of HPV infection and related complications by age have awakened an idea that HPV infection and vaccine is important thanks to the survey; in line with the purpose of our study, it shows that we can increase awareness on the subject and vaccination rates. In addition, we believe that if the HPV vaccine is added to the national vaccine program in our country, as in many countries, the incidence of HPV infection and related diseases will decrease.

\section{REFERENCES}

1. Rakel RE, Rakel DP. Aile Hekimliği. 9. Baskı. Ankara; Güneş Tıp Kitabevleri. 2019.p.218-219.

2. Kim KS, Park S, Ko K-N, Yi S, Cho YJ. Current status of human papillomavirus vaccines. Clinical and experimental vaccine research. 2014; 3(2): 168-175.

3. Smith JS, Lindsay L, Hoots B, Keys J, Franceschi S, Winer R, et al. Human papillomavirus type distribution in invasive cervical cancer and high-grade cervical lesions: a meta-analysis update. International journal of cancer. 2007; 121(3): 621-632.

4. Dursun P, Senger SS, Arslan H, Kuş̧u E, Ayhan A. Human papillomavirus (HPV) prevalence and types among Turkish women at a gynecology outpatient unit. BMC infectious diseases. 2009; 9(1): 191.

5. Schmitz M, Driesch C, Jansen L, Runnebaum IB, Dürst M. Non-random integration of the HPV genome in cervical cancer. PloS one. 2012; 7(6): 39632-39633.

6. Chesson HW, Blandford JM, Gift TL, Tao G, Irwin KL. The estimated direct medical cost of sexually transmitted diseases among American youth, 2000. Perspectives on sexual and reproductive health. 2004; 36(1): 11-19.

7. Unutkan A, Yangın HB. Üniversite öğrencilerinin human papilloma virus aşısına ilişkin bilgi ve görüşlerinin değerlendirilmesi. TAF Preventive Medicine Bulletin. 2016; 15(2): 151-158.

8. Arvas M, Gezer A. Genital HPV. İstanbul Medikal Yayıncılık. 2007. p.1-128.

9. Çetin O, Verit FF, Keskin S, Zebitay AG, Deregözü A, Usta T, et al. Ergen kızların human papilloma virüsü ve aşısı hakkındaki bilgi düzeyleri. Türk Ped Arş. 2014; 49: 142-147.

10. Özdemir G. Evaluation of Knowledge and Attitudes of Ankara Yıldırım Beyazıt University Medical Faculty Students About Human Papilloma Virus and Vaccines (dissertation). Yıldırım Beyazit University Faculty of Medicine, Department of Family Medicine; 2018.

11. Güdücü N, Gönenç G, İşçi H, Yiğiter AB, Dünder İ. Awareness of human papilloma virus, cervical cancer and HPV vaccine in healthcare workers and students of medical and nursing schools. 2012; 318-325.

12. Onsuz M, Topuzoglu A, Bilgi Z, Yılmaz M, Amuk N, Fahridin F. The evaluation of the knowledge levels and attitudes of medical students who have accomplished obstetric and gynaecological diseases internship in a medical school about human papilloma virus vaccine. TAF Prev Med Bull. 2011; 5: 557-564. 
13. Naki MM, Çelik H, Api O, Toprak S, Özerden E, Ünal O. Awareness, knowledge and attitudes related to HPV infection and vaccine among non-obstetrician-gynecologist healthcare providers. Journal of the Turkish German Gynecological Association. 2010; 11(1) :16.

14. Tolunay O, Celik U, Karaman SS, Celik T, Resitoglu S, Donmezer C, et al. Awareness and attitude relating to the human papilloma virus and its vaccines among pediatrics, obstetrics and gynecology specialists in Turkey. Asian Pacific Journal of Cancer Prevention. 2015; 15(24): 10723-10728.

15. Ozsurekci Y, Oncel EK, Bayhan C, Celik M, Ozkaya-Parlakay A, Arvas M, et al. Knowledge and attitudes about human papillomaviruses and immunization among Turkish pediatricians. 2013; 14(12): 7325-7329.

16. Dane Kocasaraç R. Evaluation of Knowledge, Attitudes and Behaviors of Ondokuz Mayıs University Medical Specialization Students about Cervical Cancer and HPV Vaccine (dissertation). Ondokuz Mayis University Faculty of Medicine, Department of Family Medicine; 2018.

17. Çeşmeci Y, Köylü B, Sulaiman J, Sancak E, Şenel S, Baki H, et al. İnternlerin gözünden HPV enfeksiyonları ve HPV aşısı. Türk Jinekolojik Onkoloji Dergisi. 2015; 18(3): 85-92.

18. Rathfisch G, Güngör İ, Uzun E, Keskin Ö, Tencere Z. Human papillomavirus vaccines and cervical cancer: awareness, knowledge, and risk perception among Turkish undergraduate students. Journal of Cancer Education. 2015; 30(1): 116-123.

\section{TABLES}

Table 1. Distribution of Sociodemographic Characteristics

\begin{tabular}{llll}
\hline & & Min-Max (Median) & Mean \pm Sd \\
\hline Age (years) & & $17-33(21)$ & $21,46 \pm 2,39$ \\
Gender & Male & 341 & $\%$ \\
& Female & 304 & 52,9 \\
Marital status & Single & 629 & 47,1 \\
& Married & 15 & 97,5 \\
\multirow{5}{*}{ Grade } & Widow & 1 & 2,3 \\
& 1.grade & 142 & 0,2 \\
& 2. grade & 94 & 22,0 \\
& 3. grade & 104 & 14,6 \\
& 4. grade & 116 & 16,1 \\
\multirow{5}{*}{ Living place } & 91 & 18,0 \\
& 5. grade & 98 & 14,1 \\
& 6. grade & 191 & 15,2 \\
& Government dorm & 29,6 \\
Smoking & Private dormitory & 72 & 11,2 \\
& Student house & 189 & 29,3 \\
& With the family & 193 & 29,9 \\
& No & 511 & 79,2 \\
Alcohol use & Yes & 105 & 16,3 \\
& Ex smoker & 29 & 4,5 \\
& No & 554 & 85,9 \\
& Yes & 81 & 12,5 \\
& Ex drinker & 10 & 1,6 \\
\hline
\end{tabular}

Table 2. Distributions of Answers Given to Questions Measuring Knowledge Level About HPV Infection 
-HPV infection causes cervical cancer and genital warts.

-HPV infection occurs only in women.

-HPV-related genital warts can be seen in both men and women.

-HPV infection ranks first among the causes of cervical cancer.

-HPV infection is transmitted from the mother to the baby through the infected birth canal sexually, body fluids or during -HPV infection is always symptomatic (showing signs).

-Monogamy, condom use and vaccination are effective in preventing HPV infection.

Correct answers are indicated in bold and italics in the table.

Table 3. Distribution of Answers Given to Questions Measuring Knowledge Level About HPV Vaccine

\begin{tabular}{|c|c|}
\hline & True \\
\hline & $\mathbf{n}$ \\
\hline -HPV vaccine has preventive properties of genital warts in both men and women and cervical cancer in women. & 312 \\
\hline -HPV vaccine should only be given to girls. & 32 \\
\hline -It is thought that administration of HPV vaccine to men may be beneficial. & 296 \\
\hline -The ideal group for HPV vaccination is young men and women between the ages of 9-26. & 290 \\
\hline -HPV vaccine should be done without being sexually active. & 263 \\
\hline -HPV vaccine can be given to any age group. & 74 \\
\hline -HPV vaccine is recommended as a single dose. & 76 \\
\hline -After the HPV vaccine, side effects such as pain, redness and headache at the injection site may occur. & 275 \\
\hline -HPV vaccine is not included in the national vaccination program and is available for a fee. & 206 \\
\hline
\end{tabular}

Correct answers are indicated in bold and italics in the table.

Table 4. Distribution of Attitudes About HPV Vaccine

\begin{tabular}{ll}
\hline Whether or not to have HPV vaccine & Yes \\
Status of wanting to get HPV vaccine $(\mathrm{n}=633)$ & No \\
& No idea \\
Reason for not wanting to get HPV vaccine $(\mathrm{n}=98)$ & No \\
& I am indecisive \\
& Not having enough awareness and k \\
& Not knowing about side effects \\
& Not to be married \\
& Not being sexually active \\
& Aşinn koruyuculuğundan endişe dus \\
Whether to have HPV vaccine if it was free $(\mathrm{n}=633)$ & The vaccine is expensive \\
& Not recommended by healthcare pro \\
& Thinking the vaccine is harmful \\
& Other \\
& Yes \\
& No \\
& I am indecisive
\end{tabular}


Ideas on adding HPV vaccine to national vaccine program

Yes

No

I am indecisive

The state of thinking that HPV infection and vaccine are important after the survey Yes

No

*Multiple selections have been made 